ПЕДАГОГИКА

DOI: $10.17805 /$ trudy.2017.6.1

\title{
АКТИВНОЕ ОБУЧЕНИЕ КАК УСЛОВИЕ ФОРМИРОВАНИЯ ОБРАЗОВАТЕЛЬНОГО ПРОСТРАНСТВА ОРГАНИЗАЦИИ СРЕДНЕГО ПРОФЕССИОНАЛЬНОГО ОБРАЗОВАНИЯ
}

\author{
Е. В. Гущина \\ Московский гуманитарный университет
}

\begin{abstract}
Аннотация: В статье рассматривается проблема выбора активных методов и технологий обучения, обеспечивающих процесс формирования у студентов профессиональных компетенций в учреждении среднего профессионального образования. На опыте колледжа Московского гуманитарного университета представлена модель формирования образовательного пространства с использованием в учебном процессе активных $и$ интерактивных форм обучения.
\end{abstract}

Ключевые слова: образовательные стандарты; образовательное пространство; профессиональные компетенции; педагогические технологии; активные методы обучения; интерактивные методы обучения; колледж

\section{ACTIVE TRAINING AS A CONDITION OF EDUCATIONAL SPACE FORMATION IN A SECONDARY VOCATIONAL ORGANISATION}

\author{
E. V. Gushchina \\ Moscow University for the Humanities
}

\begin{abstract}
The article considers the problem of choosing active methods and training technologies providing for the process of developing vocational competences of secondary vocational institution students. A model of formation of educational space with the help of active and interactive forms of training is presented by the experience of the University college.

Keywords: educational standards; educational space; vocational competences; pedagogical technologies; active methods of training; interactive methods of training
\end{abstract}

Понятие «образовательное пространство» соотносится в научных исследованиях с такими понятиями, как «образовательная система», «образовательная структура», «непрерывное образование», «образовательные стандарты», «социальные институты образования» и др. Как пишет Л. А. Пронина, «пространство не складывается само по себе или приказом сверху - оно рождается внутри педагогической действительности благодаря специально организуемой деятельности» (Пронина, 2007: Электр. ресурс). Образовательное пространство обладает свойством устойчивости на определенном временном интервале. 
Одним из важных условий формирования образовательного пространства колледжа является широкое использование в учебном процессе активных и интерактивных форм проведения занятий в сочетании с внеаудиторной работой. Мы представим это на опыте колледжа Московского гуманитарного университета (см. также: Гущина, 2015).

Переход от традиционной лекции к лекции проблемной при изучении правовых дисциплин создает возможность исследовательского отношения к содержанию лекции. Разрешая противоречия, заложенные в проблемных ситуациях, обучающиеся самостоятельно приходят к тем выводам, которые преподаватель должен сообщить в качестве новых знаний. Интересной формой проведения практического занятия по данному циклу дисциплин является дискуссия. Например, бурное обсуждение всех «за» и «против» по актуальной для возрастной категории студентов теме «Брачный контракт» позволяет обучающимся высказать свое мнение и прийти к общим выводам. Главная задача преподавателя - акцентировать разговор на правовых основах вопроса.

Лекция-провокация имеет место в работе преподавателей истории. Студентам во время лекции предлагается обнаружить ошибки и занести их в конспект. В конце лекции проводится обсуждение ошибок. Лекцияпровокация выполняет не только стимулирующую функцию, но и контрольную. С помощью системы ошибок преподаватель определяет недочеты, анализирует их в ходе обсуждения со студентами.

«Мозговой штурм» представляет собой один из эффективных приемов продуцирования идей. Преподаватели общественных и правовых дисциплин считают такой вид работы полезным, поскольку он дает представление о глубине обобщенных знаний, характере опыта студентов и уровне их подготовки. Использование этого метода помогает преподавателям адаптировать свой подход и стиль преподавания к реальным потребностям группы.

Технология проектов - образовательная технология, при которой студенты приобретают знания и умения в процессе самостоятельного планирования и выполнения постепенно усложняющихся практических заданий-проектов. Широкое применение она находит на дисциплинах «Банковское дело» и «Организация туристской деятельности». Здесь обучающиеся имеют дело с практико-ориентированными индивидуальными и групповыми проектами. В преподавании дисциплины «Организации туристской деятельности» широко представлены практико-ориентированные проекты создания туристических продуктов.

В использовании имитационных технологий важен процесс воссоздания (имитации) контекста профессиональной деятельности, ее модельного представления в обучении. Практическая работа по созданию бизнес-плана, например, во многом решает задачи профессиональной 
подготовки по экономическим дисциплинам. И зачет как защита бизнесплана (по дисциплине «Экономика организации») - продуктивная, на наш взгляд, форма промежуточной аттестации обучающихся.

Эффективной образовательной технологией является и кейстехнология. Она может быть отнесена к дискуссионным, если работа с кейсом и презентация его решения осуществляется в процессе внутригруппового взаимодействия. Технология предполагает обучение с использованием моделей реальных ситуаций. Учебные занятия по специальности «Гостиничный сервис» с использованием кейс-технологии происходят по следующему сценарию: знакомство с ситуацией, ее особенностями; выделение основной проблемы (основных проблем), выделение факторов и персоналий, которые могут реально воздействовать; предложение концепций или тем для «мозгового штурма»; анализ последствий принятия того или иного решения; решение кейса - предложение одного или нескольких вариантов (последовательности действий), указание на возможное возникновение проблем, механизмы их предотвращения и решения.

Формированию профессиональных компетенций способствует и имеющаяся в колледже система учебных лабораторий, которая позволяет создавать и решать различные производственные ситуации. В учебном «Гостиничном номере», например, студенты отрабатывают профессиональные компетенции по организации и контролю работы обслуживающего и технического персонала хозяйственной службы при предоставлении услуги размещения. Лаборатория службы продаж и маркетинга позволяет формировать профессиональные компетенции, направленные на выявление спроса на гостиничные услуги, формирование спроса и стимулирование сбыта, оценивание конкурентоспособности оказываемых гостиничных услуг, умение принимать участие в разработке комплекса маркетинга. Преподаватели профессиональных модулей специальностей «Экономика и бухгалтерский учет» и «Банковское дело» в обучении оформлению бухгалтерской отчетности, кассовых и бухгалтерских документов в ходе практических занятий используются возможности 1С. Учебные лаборатории колледжа помогают погрузить участников обучения в реальную проблемную ситуацию, являющуюся типичной для их будущей профессиональной деятельности; повысить эффективность усвоения учебного материала за счет визуализации учебного материала и эмоциональной насыщенности занятия; вырабатывать модели практических навыков обучающихся.

На занятиях по истории используется такая форма активного обучения как исторический театр, представленный в опыте преподавателя колледжа МосГУ Д. В. Осипова. Участие студентов в историческом спектакле дает возможность погрузиться в другую эпоху, познакомиться с иной 
культурой. Участие в театре - это, прежде всего, работа в коллективе, поэтому обучающиеся приобретают коммуникативные навыки, учатся находить выходы из конфликтных ситуаций, т.е. приобретают и большой социальный опыт.

Междисциплинарное портфолио по специальности «Право и организация социального обеспечения - это нечто большее, чем просто «Папка достижений» студентов. Материалы портфолио включают нормативноправовую базу какой-либо организации: благотворительного фонда, общества защиты прав слепых граждан, детского дома и т. д. Цель анализа данных документов - определить права граждан, обращающихся в данные организации. После выявления проблемы, студентам предлагается самим сформировать устав предполагаемой организации соцзащиты. Таким образом, междисциплинарное портфолио показывает самостоятельную работу обучающихся, способствует развитию навыков работы с различными видами учебной и профессиональной информации, формированию профессиональной рефлексии, а также профессиональных и общекультурных компетенций.

С целью организации самостоятельной работы студентов в колледже действует электронная система Moodle. Эффективность ее использования мы видим в экономии учебного времени через дистанционное взаимодействие и возможность индивидуализировать выполнение заданий.

Широкий спектр применяемых в колледже технологий отбирается не «вслепую», а на основе дифференциации их под особенности конкретной специальности. Нельзя выработать единую образовательную технологию. Есть ряд специальностей, которые по своему содержанию предполагают практическую деятельность и выполнение конкретных заказов («Реклама», «Бухгалтерский учет»). Здесь больший акцент делается на проектную деятельность. Специальности «Туризм», «Право и организация социального обеспечения», «Гостиничный сервис» предполагают разрешение проблемных ситуаций, поэтому здесь актуальны кейс-технологии и дискуссии.

Вопросы выбора образовательной технологии, наилучшей для существующих условий ее применения, составляют важнейшую сторону деятельности преподавателя. Имеется некоторое множество образовательных технологий и множество факторов, предопределяющих выбор технологии (Панфилова, 2009: 16). К последним можно отнести приоритетные цели СПО; специфику преподаваемой учебной дисциплины; цели, задачи и содержание материала конкретного занятия; уровень подготовленности и личные качества самого преподавателя; уровень подготовленности студентов; уровень материальной оснащенности учебного процесса.

Активность и заинтересованность педагогов повышает учебную мотивацию студентов, выводит образовательный процесс за рамки «скучных» 
уроков и позволяет сформировать не только профессиональные, но и общие социокультурные компетенции молодых специалистов. Это взращивает в них компетенцию успеха. «Главное для человека, которому жить в условиях сумасшедших перемен и скоростей XXI в., - это не только ремесло, специальность, которые позволяют ему кормиться самому и кормить свою семью, но также овладение тем кругом достоверных традиционных и новых знаний, без которых он не сумеет объяснить себе и понять, зачем живет, как надо жить, каким надо быть», считает И. М. Ильинский (Ильинский, 2010: 66). Обладание актуальными знаниями и умениями, способность реализовать свой потенциал в условиях современного общества, готовность к мирному созиданию, как пишет А. В. Костина (Костина, 2016), позволят сформировать ценностный мир личности.

\section{СПИСОК ЛИТЕРАТУРЫ}

Гущина, Е. В. (2015) Формирование образовательного пространства Колледжа МосГУ как системы профессиональной подготовки студентов в свете реализации ФГОС СПО // Качество образования в школе. № 4. С. 21-25.

Ильинский, И. М. (2010). Играющий триумвират: образование, политика, право. М. : Изд-во Московского гуманитарного университета. 134 с.

Костина, А. В. (2016) Общество потребления и ценности российской цивилизации // Знание. Понимание, Умение. № 4. С. 45-55. DOI: 10.17805/ zpu.2016.4.3

Панфилова, А. П. (2009) Инновационные педагогические технологии: Активное обучение : учеб пособие для студ. высш. учеб. заведений. М. : Издат. центр «Академия». 192 с.

Пронина, Л.А.(2007) Открытое культурно-образовательное пространство как образовательная парадигма общества знаний [Электронный ресурс] // Аналитика культурологии. № 8. URL: http://www.analiculturolog. ru/journal/archive/item/1649-открытое-культурно-образовательноепространство-как-образовательная-парадигма-общества-знаний.html (дата обращения: 12.09.2017).

Дата поступления 30.11.2017 2.

Гущцна Елена Валентиновна - директор Колледжа Московского гуманитарного университета, член-корреспондент Петровской академии наук и искусств. Адрес: 111395, Россия, г. Москва, ул. Юности, д. 5, корп. 11. Тел.: +7 (499) 374-71-83. Эл. адрес: elena_gushchina@mail.ru 
Gushchina Elena Valentinovna, Director, College, Moscow University for the Humanities; Associate Member, Petrovskaya Academy of Sciences and Arts. Postal address: 5, Yunosti St., Moscow, Russian Federation 111295. Tel.: +7 (499) 374-71-83. E-mail: elena_gushchina@mail.ru

\section{Для цитирования:}

Гущина Е. В. Активное обучение как условие формирования образовательного пространства организации среднего профессионального образования [Электронный ресурс] // Научные труды Московского гуманитарного университета. 2017. № 6. URL: http://journals.mosgu.ru/trudy/article/view/617 (дата обращения: дд.мм.гг.). DOI: 10.17805/trudy.2017.6.1 